\title{
Post-Translation Editing of Scientific and Technology Texts under Chesterman's Translation Norm
}

\author{
Huijun Ren, Qijing Lu, Jingya Pang, Yi Ling \\ School of Arts and Sciences, Shaanxi University of Science and Technology, Xi'an, China \\ Email: renhj@sust.edu.cn
}

How to cite this paper: Ren, H. J., Lu, Q. J., Pang, J. Y., \& Ling, Y. (2021). PostTranslation Editing of Scientific and Technology Texts under Chesterman's Translation Norm. Open Journal of Modern Linguistics, 11, 49-56.

https://doi.org/10.4236/ojml.2021.111004

Received: December 7, 2020

Accepted: January 30, 2021

Published: February 2, 2021

Copyright (๑) 2021 by author(s) and Scientific Research Publishing Inc. This work is licensed under the Creative Commons Attribution International License (CC BY 4.0).

http://creativecommons.org/licenses/by/4.0/ (c) (i) Open Access

\begin{abstract}
The development of science and technology brings about the alternating progress of technique in all the industries. Machine translation has attracted the attention and the discussion among the whole translation industry. From the discussion on the quality of the translation produced by machines to the debate on whether machines can completely replace human's role in translation activities. The author believes that post-translation editing can make up for the shortcomings of machine translation under the mode of "human-computer interaction". This paper, from the perspective of Chesterman's translation norms, explores the positive role of post-translation editing in scientific and technology text translation through the "human-computer interaction" in effectively improving the translation's quality, in the current wave of scientific and technological development. The author will give some focuses for the post-translation editing of the Scientific and technology texts from the perspective of Chesterman's translation norms in this paper. It aims to improve the translation quality of the Scientific and technology texts to the greatest extent with the aid of machine translation.
\end{abstract}

\section{Keywords}

"Human-Computer Interaction", Post-Translation Editing, Translation Norm, Machine Translation, Scientific and Technology Text Translation

\section{Introduction}

\subsection{The Background of the Post-Translation Editing}

With the rapid update and iteration of science and technology, the translation industry is also developing with it, gradually changing from the traditional ar- 
tificial translation to the computer-aid translation. From translators' assiduously working on the case and using reference books to convey culture and information by pen and paper, to today's fast-paced machine translation, the translation industry strives for efficiency as well as quality. The research history of machine translation can be traced back to the 1930s and 1940s. In the early 1930s, French scientist G.B. Artsouni came up with the idea of using machines for translation. In 1949, W. Weaver published the Translation Memorandum, which formally put forward the idea of machine translation. After 60 years of ups and downs, machine translation has experienced a tortuous and long road of development. The merits of machine translation have aroused many controversies. Since the emergence of machine translation, it has experienced continuous improvement and perfection. In 2014, Cui Qiliang cited industry data to show that post-translation editing is receiving more and more attention from translation companies (Cui, 2014). Although machine translation software is gradually becoming mature, it still has some "inherent problems". In its 2017 Machine Translation Market Report, TUAS argued that the new translation model, known as "Machine Translation + Post-translation editing" (MT + PE), could become the primary production environment for the translation industry within the next five years (2022) (Joscelyne, 2017). The "human-computer interaction" mode will be maintained for a long time. Professor Feng Quangong pointed out that "Post-translation editing means that in the practice of translation, the original text is first translated by machine, and then the translation produced by machine is edited and modified by the translator for a second time" (Feng \& Cui, 2016). Advantages of the post-translation editing in the processing of scientific and technology texts are unprecedented. Scientific and technology texts emphasize its professionalism, logicality, rigor and accuracy (Sun \& Si, 1997).

\subsection{The Significance of the Research}

"Google translation", for example, is extremely sensitive to Scientific and technology texts' professional terminology, and the accuracy of translation, produced by Google, is very high. It saves the translators a lot of time to look up materials, and divides sentence structures correctly, which enables the translator to quickly clarify sentence components and greatly reduces the time spent in the initial translation process. However, machine translation for various Scientific and technology texts is not able to produce qualified translations that fully meet the needs of customers, and many "stupid translations" in the machine translation are often criticized.

Therefore, the post-translation editing becomes more and more important. Nevertheless, the level of translators engaged in post-translation editing has great disparity. Some of them are not even English majors or professional translators, so they do not have translation qualifications, but only have basic knowledge of technology and software operation, which makes the translations produced by such translators still not meet the requirements of customers. 
The author will give some focuses for the post-translation editing of the Scientific and technology texts from the perspective of Chesterman's translation norms in this paper.

\section{Brief Introduction of Translation Norm Theory}

Gideon Toury (1888-1968) is famous Israeli translation theorist. In the field of translation, Gideon Toury has been recognized as the first scholar to systematically discuss translation norms (Toury, 1980). He defined the "norm" as "a category of descriptive analysis of translation, which is the values and concepts shared in a certain target language society, such as what is right and what is wrong, what is proper and what is not appropriate, and translating the correct and appropriate principles of translation behavior in a particular situation" (Toury, 1980). Toury's "translation norm" is inherited and developed by Andrew Chesterman, who believes that the norm is the dominant meme in a specific historical period (Chesterman, 1997). In this view, he draws on linguist Bartsch's definition of norms, that is, norms are regarded as the "social existence of related correct ideas" rather than as "orders or regulations issued by superiors to subordinates" (Bartsch, 1987).

Chesterman believes that "Norms, as a social reality, are the dominant concepts accepted by a certain group that can promote useful behaviors and highly influence people's thinking and behavior" (Chesterman, 1997). Translation, as a social behavior, is also constrained and guided by a certain code of conduct. It can be considered that the norms and the concepts shared and expected by a certain cultural group, which restricts or guides the appropriateness of translation behavior, are translation norms. Chesterman divides the translation norms into two categories: the expectancy norm and the professional norm. Professional norms can be divided into three types: the responsibility norm, the communication norm and the relationship norm. The norms of these four dimensions require the translation to meet the expectations of the target language readers in terms of grammar, acceptability and text style, and also require the translator to guide and adjust the translation process accordingly (Huang, 2019).

The expectancy norm is established by the target readers' expectation for the translation, which may be influenced by such factors as economy or ideology and cultural authority. The target language readers also need to have a certain level of expertise, and their expectations on the translation can play a supervisory and restrictive role on the translator. Professional norms restrict the process of translation, which is based on the strategies or methods adopted by professional translators. The responsibility norm is the embodiment of the translator's responsibility, and the translator shall be responsible for all parties involved in the translation activities, such as the original author, the translation client, the translator himself, the target reader and other relevant parties, which can also be regarded as a code of ethics. The communication norm is the embodiment of information transmission, and translators shall try their best to make translation 
activities communicate with all parties, so as to achieve the optimal translation effect, which can also be seen as a social norm. The relationship norm is the norm of language, which means that the translation text and the original text shall maintain a certain similarity in language.

The Toury's translation norm is universal for any translator while the Chesterman's translation norm is suitable only for professional translators (Zhou \& Yang, 2016). Professional translators need to have a deep and thorough understanding of the importance of translation. Whether the translation is correct or not and how good it is will inevitably produce completely different effects (Chen, 2016). As a consequence, the author will take Chesterman's translation norms theory as the guide to discuss and analyze the positive influence of the posttranslation editing of Scientific and technology texts.

\section{Post-Translation Editing of Scientific and Technology Texts under Chesterman's Translation Norm Theory}

First of all, under the guidance of the expectancy norm, the translators shall always be based on the expectations of target readers during the process of the post-translation editing and be good at finding inappropriate wording in machine translation. The target language readers involved in the expectancy norm usually have some authority, which means that translators shall meet their expectations or obtain their approval. In the evaluation of Scientific and technology text translation, the target language readers that meet the requirements include scientists, reviewers of the Scientific and technology text, revisers of the Scientific and technology text, and technicians of science and technology. When reediting the translation produced by machine translation, the translator shall consider the readers' cognitive habits, ways of thinking, language characteristics, aesthetic expectations, etc. Although machine translation can provide effective assistance in translation, the translator shall carefully deal with its shortcomings (Lai, 2012).

Case 1: 每一个临床样本在进行临床测试之前, 都应熟悉产品指导说明书, 在熟悉该测试系统之后进行临床测试。

MTese: Each clinical sample should be familiar with the product instruction manual before clinical testing and clinical testing after familiarity with the test system. (From Google)

Revision: The product instructions and the testing system must be mastered before testing each clinical sample.

In Case 1, the Scientific and technology terms in machine translation are relatively accurate, and the reedited translation retains the translation of these terms. However, due to the limitations of word-to-word translation, machines cannot flexibly adapt to the sentence patterns. There are semantic errors in the translation of the machine translation. The coreect logical subject of this sentence is not “临床样本”, but “产品说明书” and “测试系统”.

Secondly, under the guidance of the responsibility norm, translators need to actively communicate with customers and make editing according to their re- 
quirements. Some customers require the translation of the Scientific and technology texts to be concise and complete, and sometimes require the translation of certain words or sentence patterns. They even require that the translation be different from the machine translation, and the translator must edit and modify the translation according to the customer's requirements.

Case 2: Drawings, specifications, and other information obtained by Contractor from Company or Owner in connection with the Work shall be held in confidence by Contractor and shall not be disclosed to third parties or used by Contractor for any purpose other than for the performance of Work or as authorized in writing by Company.

MTese: 承包商从公司或所有者处获得的与工作有关的图纸, 规格和其他信 息应由承包商保密, 不得向第三方披露或由承包商用于除工作以外的任何其 他目的或作为由公司书面授权。

Revision: 海工应对从业主或与本工程有关的大业主处获得的图纸、说明书 及其它保密的信息, 不得向第三方透露或用于海工实施本工程或业主书面授 权以外的目的。

Case 2 is a manuscript translated by the author. Before accepting the manuscript, the customer sent their translation requirements, including the format requirements, style, language, etc. They clearly marked in the file, the "Contractor" shall be translated as “海工”, the “Company” shall be translated into “业主”, and the "Owner" shall be translated into “大业主”. The above words are familiar words but show an uncommon meaning, and the machine translation can't identify the professional meanings of them, so the translator shall pay special attention to translate these words when editing in line with the responsible attitude to customers.

Thirdly, translators under the guidance of the communication norm shall carefully distinguish the differences between the source language and the target language, and keep an eye out to the context as well. Since the Scientific and technology texts are objective and concise, translators shall pay attention to avoid the non-written language and the redundant and verbose expressions. The machine translation often appears translation pretermission or some excessive parsing sentences, and translates each phrase or even every Chinese character mechanically. Meanwhile, the machine translation with the words count have limitations, and the translation file can contain only a certain number of words of the original text, so it can't deal with the whole context, which would produce an "incongruous" translation when dealing with the split sentences.

Case 3: 胎面是轮胎与路面接触的部分, 设计有不同的花纹, 以保障在干燥、 潮湿、泥浆和雨雪路面状况下, 车辆均能提供牵引力, 以防止打滑的出现。

MTese: The tread is the part of the tire that is in contact with the road surface. It is designed with different patterns to ensure that the vehicle can provide traction under dry, wet, mud and rain and snow conditions to prevent the occurrence of slip.

Revision: The tread is the part of the tire that is in contact with the pavement. 
It is designed with different patterns to ensure that the automobile can provide traction under dry, wet, mud and rain, and snow conditions to prevent skidding.

Case 3 shows the advantages of machine translation. The author adopts most of machine translations. There are few frequent repetition and emphasis in Chinese, while English is concise. For instance, “胎面” is translated into "tread", not “tire tread”, and “防止打滑的出现” is translated into "prevent skidding” instead of "prevent the occurrence of slip". In the post-translation editing, we should rationally analyze the different expression habits of English and Chinese to provide the best translation for customers.

The fourth is the relationship norm, which means that the translator should not ignore the original text but only pay attention to the translation when editing. Many translators consider the post-translation editing to be a simple modification of the machine translation. In order to produce a high-quality translation file, translators must be on the basis of deeply understanding the original texts, and then to meticulously consider the translation of words, grammar, style, etc. Translators shall be faithful to the original texts and do not drop the characteristics of the target language, making a balance between the original text and the translation, to form a "similarity" relationship between the two of them.

Case 4: 勤勉尽责原则。遵循反洗钱法律法规和我行内部制度要求, 切实履 行本机构和岗位范围内客户身份识别的工作职责，收集真实、有效和完整的 客户信息，做到 “了解你的客户”，对客户身份资料及交易记录妥善保存。

MTese: The principle of diligence. Comply with anti-money laundering laws and regulations and internal system requirements of our bank, earnestly perform the job responsibilities of customer identification within this institution and the scope of positions, collect true, effective and complete customer information, and achieve "know your customers" and check customer identity information and transaction records are properly kept.

Revision: The principle of being diligent and responsible. The Bank shall observe anti-money laundering laws and regulations and its internal policies and requirements, earnestly fulfill the job responsibilities of customer identification within the scope of the Bank and positions, collect true, effective, and complete customer information, achieve "Know Your Customer", and properly keep customer identity information and transaction records.

Case 4 shows the "similarity" relationship between the high-quality translation and the original text. The translation of “勤勉尽职原则” is “The principle of diligence" in machine translation, which makes the expression of meaning more concise and direct, but losses the rhythm of the original text. It is necessary that the translation shall be reedited to "The principle of being diligent and responsible". The overlapping of synonyms, "diligent and responsible", can embody the emphasis of the meaning in the original text. In the absence of the subject in the original text, machine translation defaults to translating all the sentences into passive voice, which is logically ambiguous. Through the post-translation editing of the translator, the recessive subject “银行” in the original text is translated, and the sentence is translated into the active sentence, which makes 
the logic between the sentences clearer and the meaning more fluent. In conclusion, during the process of the post-translation editing, translators shall take the linguistic style and the structure of the original text into account, so as to maximize the meaning of the original text while ensuring the characteristics of the target language and form a balanced "similarity" relationship between the original texts and the translations.

\section{Conclusion}

From the above, with the help of the powerful development of science and technology, the post-translation editing, under the mode of "human-computer interaction", has greatly improved the production efficiency and the translation quality of the current translation industry, but the uneven quality of translators is also a major factor hindering the development of the translation market.

At present, machine translation cannot completely replace the role of human beings in translation activities, and the final quality of the translation is still controlled by human beings. In scientific and technology text translation, machine translation performs better than that in literary text translation. However, in the face of complex language structures, such as multi-short sentence paralle structures and long sentences without subjects, it still needs manual reading and modification after the initial processing of machine translation.

The author is inspired in the Chesterman's translation norm theory, and gives some tips drawn by the translation of the Scientific and technology texts from the four perspectives of the expectancy norm, the responsibility norm, the communication norm and the relationship norm. If the translators keep in line with the four above norms to operate the post-translation editing process, the quality of the translations would be much better. All these suggestions in this paper are aimed to improve the quality of the translation of the Scientific and technology text with the help of the machine translation.

\section{Conflicts of Interest}

The authors declare no conflicts of interest regarding the publication of this paper.

\section{References}

Bartsch, R. (1987). Norms of Language: Theoretical and Practical Aspects (p. xii). London: Longman.

Chen, J. L. (2016). The Relationship and Reference between the Translation View of Reception Aesthetics and Ecological Translation Studies. Journal of Guangdong University of Foreign Studies, No. 2, 111-117+125.

Chesterman, A. (1997). Memes of Translation: The Spread of Ideas in Translation Theory. Amsterdam: John Benjamins. https://doi.org/10.1075/btl.22

Cui, Q. L. (2014). On Post-Translation Editing in Machine Translation. Chinese Translators Journal, 35, 68-73.

Feng, Q. G., \& Cui, Q. L. (2016). Post-Translational Editorial Research: Focus Analysis 
and Trends. Shanghai Journal of Translators, 6, 67-74+94.

Huang, X. L. (2019). On the Translation of Economic Text from the Perspective of Chesterman's Translation Norm: Case Study of Translating Structured Settlements: A Guide for Prospective Sellers. Nanjing: Nanjing University.

Joscelyne, A. (2017). Machine Translation Market Report. TAUS.

Lai, D. F. (2012). The Translation of Tourism Publicity under the Expectation of Reception Aesthetics. Journal of Zhejiang Tourism Vocational College, 3, 67-69+76.

Sun, B. Y., \& Si, Y. H. (1997). Introduction to Science and Technology Communication. Beijing: Tsinghua University Press.

Toury, G. (1980). In Search of a Theory of Translation. Tel Aviv: The Porter Institute for Poetics and Semiotics, Tel Aviv University.

Zhou, Y. L., \& Yang, X. M. (2016). The Comparative Study on the Toury's and Chesterman's Translation Norms. Science \& Technology Version Journal, 19, 51+64. 